\title{
AVALIAÇÃO DA USABILIDADE DE UM WEBSITE DE SISTEMMA DE BIBLIOTECAS UNIVERSITÁRIAS
}

\section{USABILITY EVALUATION OF A UNIVERSITY LIBRARY SYSTEM WEBSITE}

\author{
Silvia Regina Ferreira Limaa \\ Ariadne Chloe Furnival ${ }^{\mathrm{b}}$
}

\begin{abstract}
RESUMO
Objetivo: Avaliar a usabilidade da plataforma de um sistema de bibliotecas universitárias e do portal de uma biblioteca específica desse sistema. Metodologia: Os participantes da pesquisa (graduandos) foram observados enquanto realizaram uma série de tarefas especificadas. Subsequentemente, foram questionados sobre suas opiniões e percepções quanto à facilidade e satisfação na realização das tarefas, e a respeito da visualização, disponibilização e acessibilidade dos recursos. Resultados: Foi possível observar cada usuário interagir com a interface do sistema na realização das tarefas através da barra de rolagem, mouse, percepção das cores do menu, na busca da ajuda nas diversas abas, avaliando a facilidade com que cada usuário chegou ao resultado das tarefas e quais as dificuldades encontradas. Conclusão: A pesquisa auxilia os desenvolvedores de sistemas na elaboração de interfaces mais fáceis e práticas. Com relação ao sistema de bibliotecas avaliado, e particularmente a respeito do catálogo, este poderia ser melhor rotulado para que seja mais facilmente localizado, assim ajudando o usuário a identificar e localizar uma obra no acervo. Como importante ferramenta na busca por informações na Web, o site do sistema deve seguir as regras da usabilidade para que sejam eficientes, de linguagem acessível, aprendizado fácil e boa visibilidade.
\end{abstract}

Descritores: Tecnologia da informação. Usabilidade. Interação Humano-computador. Recuperação de informação.

\footnotetext{
a Graduação em Biblioteconomía pela Universidade Federal de São Carlos (UFSCAR). E-mail: slima@estudante.ufscar.br

b Doutora em Política Científica pela Universidade Estadual de Campinas (UNICAMP). Docente do Departamento de Ciência da Informação da Universidade Federal de São Carlos (UFSCAR). E-mail: chloe@ufscar.br
} 


\section{INTRODUÇÃO}

A tecnologia da informação foi incorporada à rotina de atividades do bibliotecário, o qual deve estar constantemente atualizado quanto às novas plataformas digitais disponíveis. Desta forma, suas atividades em uma unidade de informação são intermediadas pelo uso de ferramentas que o auxiliam na organização, disseminação e recuperação da informação. Essas ferramentas ou sistemas visam conferir agilidade aos serviços prestados, aperfeiçoando o trabalho do profissional da informação e poupando o tempo do usuário em suas pesquisas (ZAMITE, 2016).

A qualidade da interação do usuário com os ambientes informacionais digitais está relacionada não só ao atendimento de suas necessidades informacionais, mas também às diversas possibilidades que esse ambiente pode proporcionar. Portanto, o planejamento de um ambiente digital deve considerar tanto a facilidade de interação como o uso criativo do ambiente pelo usuário. $A$ combinação das qualidades de estética e funcionalidade, embora possa parecer uma atividade complexa para os desenvolvedores, pode resultar em um produto satisfatório, desde que bem planejado (VECHIATO, 2010). A essas qualidades, quando aplicadas conjuntamente em um ambiente informacional digital, dá-se 0 nome de "usabilidade". De acordo com a norma NBR 9241-11 "Requisitos Ergonômicos para Trabalho de Escritórios com Computadores Parte 11 Orientações sobre Usabilidade" (ABNT, 2000), usabilidade pode ser definida como "[...] medida na qual um produto pode ser usado por usuários específicos para alcançar objetivos específicos com eficácia, eficiência e satisfação em um contexto específico de uso" (ABNT, 2000, p. 3). No contexto das bibliotecas universitárias, então, a usabilidade de sistemas digitais torna-se um fator fundamental para promover a disseminação da informação e do conhecimento.

Os usuários das bibliotecas atualmente contam com inúmeras ferramentas interativas para localização dos recursos informacionais de que necessitam. Para ajudar os usuários nesta tarefa, muitas bibliotecas disponibilizam catálogos computadorizados denominados Catálogos Online de Acesso Público (tradução da sigla em inglês OPAC - Online Public Access 
Catalogue), que hoje em dia podem ser acessados por meio da Web (YESMIN; AHMED, 2016), o que também é o caso para a maioria das bibliotecas universitárias, sobretudo as públicas. Isso permite que seu acervo possa ser consultado pela internet, com módulos que possibilitam e disponibilizam outros serviços como reserva, renovação de empréstimos, acesso aos repositórios institucionais, entre outros, expandindo suas atividades. Para tanto, é necessário que o website apresente na sua interface uma facilidade de navegação para que os seus usuários consigam acessar e recuperar a informação.

Porém, mesmo que as últimas gerações de usuários - as chamadas gerações $X, Y, Z$ - inegavelmente possuam desteridade e habilidades quase que "intuitivas" no uso de sistemas na Web, a usabilidade desses sistemas ainda é fator determinante para a eficácia na recuperação da informação e realização com sucesso de determinadas tarefas informacionais, além de propiciar uma experiência agradável ao usuário. Nesse sentido, a boa usabilidade tem o potencial de garantir o retorno e uso contínuo do sistema pelo usuário.

Diante do exposto, o objetivo do estudo aqui relatado foi o de avaliar, junto aos usuários, a usabilidade da interface de um sistema de bibliotecas universitárias de uma universidade pública brasileira. Os objetivos específicos foram: levantar e analisar as avaliações que os usuários - graduandos da universidade proprietária do sistema sendo avaliado, além de outras IESs - tem da usabilidade da interface online2 2 do sistema de bibliotecas; e levantar e analisar as avaliações dos usuários a respeito da usabilidade do catálogo online do sistema.

\section{REVISÃO DA LITERATURA}

O conceito de usabilidade estabelece um conjunto de fatores relacionado com a facilidade e o esforço necessários para os usuários aprenderem e utilizarem um sistema de informação. Segundo Nielsen e Loranger:

A usabilidade é um atributo de qualidade relacionado à facilidade de uso de algo. Mais especificamente, refere-se à rapidez com que os usuários podem aprender a usar alguma coisa, a eficiência deles ao usá-la, o quanto lembram daquilo, seu grau de propensão a erros e o quanto gostam de utilizá-la. Se as 
pessoas não puderem ou não utilizarem um recurso, ele pode muito bem não existir (NIELSEN; LORANGER, 2007, p. xvi).

O termo usabilidade surgiu na década de 1980 no campo da Ciência Cognitiva, nas áreas da Psicologia e Ergonomia, em substituição à expressão user-friendly (amigável em português) (DIAS, 2003). De acordo com Vechiato e Vidotti (2012), a teoria da usabilidade é interdisciplinar, reunindo e relacionando conhecimentos dos seguintes campos de pesquisa científica:

- Interação Humano-Computador: interação entre usuários e interface digital, em relação à forma e conteúdo. A coleta de informações é o conceito mais importante que emergiu da pesquisa sobre Interação Humano-Computador (IHC) desde 1993. (NIELSEN, 2007).

- Ergonomia e Ciências Cognitivas: relação entre o ambiente de interação e comportamento humano, com enfoque nas necessidades das pessoas e seus processos cognitivos;

- Arquitetura da Informação: estruturação e organização da informação disponibilizada nos ambientes em todas as fases do processo de desenvolvimento, sob o ponto de vista dos usuários e desenvolvedores;

- Comportamento Informacional: o comportamento humano em relação à informação influencia o comportamento de busca e uso de informação em ambientes informacionais digitais, uma vez que grupos de usuários de diferentes culturas, sexos, idades, etc. possuem formas diversas de compreender sua necessidade informacional, buscando informações em diferentes fontes e canais de informação.

Em ambientes digitais, a usabilidade se refere à qualidade da interação entre usuários e esses ambientes durante o seu uso (VECHIATO; VIDOTTI, 2012). Mais especificamente, essa "qualidade de interação" pode ser traduzida para a facilidade experimentada pelo usuário em realizar uma determinada atividade eficazmente, prescindindo da necessidade de treinamentos específicos ou de intermediação por profissionais especializados para o uso do sistema em questão (MOURA, 2018). Isto é, o sistema idealmente seria "intuitivo" no seu uso.

A NBR ISO/IEC 9126-1 - norma técnica acerca da qualidade de produtos de engenharia de software - define a usabilidade como a "Capacidade do produto de software de ser compreendido, aprendido, operado e atraente ao usuário, quando usado sob condições especificadas" (2003, p. 9), e é um atributo da qualidade interna e externa do software. De acordo com esta norma, a 
usabilidade é, por sua vez, dividida entre os aspectos de inteligibilidade: é fácil entender os conceitos usados no sistema? apreensibilidade: é fácil aprender a usar o sistema? e operacionalidade: é fácil operar e controlar a operação do sistema? A atratividade do sistema - o propósito de tornar o software mais atraente para o usuário mediante o uso de certas cores e layout gráfico - é também considerada como um atributo da sua usabilidade. Vemos que a usabilidade e a acessibilidade são fortemente inter relacionadas, mas o atributo atratividade de um sistema pode ser avaliado muito positivamente por um grupo de usuários que não tenha necessidades especiais, ao mesmo tempo em que pode ser avaliado como muito pouco acessível por usuários com essas necessidades especiais.

Vechiato (2010, p. 106), a partir da investigação dos princípios de usabilidade por diversos autores do campo, elaborou uma síntese dos princípios de usabilidade:

- Prevenção e tratamento de erros: O sistema deve apresentar baixa taxa de erros. Caso ocorram, este deve disponibilizar formas de tratamento destes erros para que o próprio usuário possa resolvê-los.

- Consistência: O sistema deve apresentar padronização em suas ações constituintes, tornando-se desta forma, consistente e sem exigir que o usuário reaprenda a utilizá-lo a cada nova ação realizada.

- Feedback: O sistema deve fornecer respostas ao usuário ao final de cada ação realizada, por meio de mensagens, por exemplo.

- Controle: O usuário deve possuir controle sobre o sistema, e não o contrário.

- Eficácia e eficiência: O usuário, ao conhecer o sistema, analisa o quanto este pode o auxiliar no alcance de seus objetivos. A partir do momento que o usuário interage com ele, este deve fornecer subsídios para que o torne frequente, realizando suas ações de forma rápida e satisfatória.

- Fácil aprendizado O novo usuário de um sistema ou o usuário em um sistema reestruturado, busca utilizá-lo com frequência. Portanto, deve ser fácil de usar a partir de uma interface intuitiva.

- Flexibilidade: O usuário deve considerar todas as diversidades humanas possíveis do seu público alvo.

- Visibilidade: Os usuários devem encontrar no sistema as 
informações desejadas de forma facilmente perceptíveis e claras.

- Compatibilidade: O sistema deve fornecer similaridades das ações com os sistemas já conhecidos pelos usuários e com o cotidiano deles.

- Fácil memorização: Ao aprender a interagir com o sistema, o usuário deve lembrar como fazê-lo ao utilizálo novamente.

- Uso equitativo: A partir da definição do público-alvo do sistema, este deve atender a todos: usuários experientes ou não e se possível, outros usuários fora do grupo que buscam informações nele.

- Affordance O sistema deve convidar os usuários a realizar determinadas ações a partir de pistas.

- Ajuda: O sistema deve fornecer módulos de ajuda para resolver problemas enfrentados no decorrer do seu uso.

De modo geral, nosso contato com um sistema e por extensão, nossa experiência da sua usabilidade, é por meio da interação e experiência da interface desse sistema. A interface "compreende toda a porção do sistema com a qual o usuário mantém contato físico (motor ou perceptivo) ou conceitual durante a interação" (BARBOSA; SILVA, 2010, p. 25). No entanto, a usabilidade não é uma característica intrínseca ao sistema e sua interface, mas uma que resulta da dinâmica de interação entre o usuário, a interface, a velocidade de processamento do computador e a tarefa sendo realizada (CYBIS; BETIOL; FAUST, 2010), realização essa que deva ser eficaz, eficiente e dar uma sensação de satisfação ao usuário.

Os problemas mais comuns com a usabilidade das interfaces de sistemas dizem respeito a seu design, que poderiam se manifestar em, entre outros aspectos, a confusão de cores (p.ex. contraste de cores pobre) e seu layout (p.ex. inconsistência da posição de botões e menus); o conteúdo, por exemplo falta certa informação ou a informação é má-escrita em frases complexas e prolixas, ou que contém muito jargão; a rotulação confusa em links e botões, suscitando o sentimento de incerteza no usuário sobre o que vai acontecer quando se clica num link ou botão, o que acarreta na navegação não-intuitiva pela qual o usuário experimenta dificuldade em encontrar e navegar para a parte desejada do site; a má funcionalidade, pela qual o sistema não funciona como o 
usuário espera em relação às funções apresentadas, por exemplo, o usuário se cadastra no sistema, faz o login nele, mas logo depois, tem que fornecer os mesmos dados que já forneceu no cadastro (NIELSEN; 2007). Bons designs devem obter um bom equilíbrio entre a aparência estética, a quantidade ideal e o tipo de informações por página (ROGERS; SHARP; PREECE, 2013).

No que diz respeito aos métodos usados para avaliar a usabilidade, podem ser identificadas duas perspectivas gerais: perspectiva objetiva, em que a usabilidade pode ser medida e avaliada por meio da observação do sujeito no decorrer do desenvolvimento de tarefas de interação (eficácia e eficiência); e perspectiva subjetiva, em que se conta com as opiniões do sujeito a respeito da facilidade e da satisfação de uso após a conclusão das tarefas (MONTERO, 2006; PADOVANI; SCHLEMMER; SCARIOT, 2012). Por exemplo, medidas de eficácia poderiam ser voltadas ao número de tarefas concluídas ou o número de usuários que conseguiram completar a tarefa corretamente. Por sua vez, medidas de eficiência poderiam focar no número de toques de teclas ou cliques no mouse necessário para completar uma tarefa e/ou medir o tempo tomado/requisitado para completá-la. Medidas de satisfação focam nas expressões, gestos e comentários dos usuários ao usar o sistema, e a frequência de reclamações verbalizadas pelos usuários.

No tocante ao tamanho da amostra de usuários necessário para realizar um estudo de avaliação de usabilidade, Nielsen (1993 apud WILDEMUTH, 2009) notoriamente argumentou que apenas com cinco ou seis usuários, é possível identificar $80 \%$ dos problemas de usabilidade enquanto outros autores determinaram que um tamanho de amostra maior é necessário para identificar uma proporção significante dos problemas de usabilidade de novos sistemas ou websites (FAULKNER, 2003; SPOOL; SCHRODER, 2001 apud WILDEMUTH, 2009). Na sua revisão da literatura, Wildemuth (2009) observa que a técnica de protocolo verbal é frequentemente utilizada para colher os pensamentos e percepções de usuários a respeito da interface e seus possíveis equívocos quanto à funcionalidade dela. Wildemuth (2009) também relata o estudo de Edlin (2005), que comparou a efetividade de dois tipos de protocolo verbal no seu estudo remoto de usabilidade. Um protocolo verbal foi coletado pelo telefone, 
sendo que a pesquisadora estava no telefone com o participante do estudo enquanto este interagia com o sistema sendo avaliado. A outra versão do protocolo verbal usou SMSs entre pesquisadora e participante. Edlin (2005 apud Wildemuth) conclui que os protocolos verbais colhidos pelo telefone foram muito mais ricos e detalhados que aqueles coletados via SMS.

\section{PROCEDIMENTOS METODOLÓGICOS}

A pesquisa pode ser classificada como qualitativa, utilizando curtas entrevistas com questões abertas e estruturadas, e observação de uma amostra de participantes realizando tarefas no site do sistema de bibliotecas universitárias que foi o objeto do estudo. Esse sistema reúne quatro bibliotecas universitárias da mesma instituição, e possui um portal de busca integrada que é um catálogo online que integra os recursos informacionais e digitais disponíveis no sistema. Os acervos das bibliotecas estão disponibilizados em um catálogo global, que possibilita a consulta simultânea ou em cada acervo de forma independente. $\mathrm{O}$ acesso e a consulta são livres e abertos ao público em geral. $O$ empréstimo é permitido para a comunidade acadêmica da instituição e também para pessoas residentes no município e seus distritos administrativos.

Como esta pesquisa envolvia interações e levantamento de dados com pessoas (participantes da pesquisa), foi necessário enviar o projeto, o Termo de Consentimento Livre e Esclarecido (TCLE) e os instrumentos de coleta de dados (questionário, ficha de observação) para análise pelo Comitê de Ética (CEP) da instituição da primeira autora. A pesquisa de campo foi realizada de 22 de julho a 08 de agosto, no ano 2020. Os participantes foram convidados aleatoriamente, primeiramente pelo WhatsApp de um grupo (do qual a primeira autora participa) de graduandos do curso de Bacharelado em Biblioteconomia e Ciência da Informação, grupo esse que reúne as turmas dos anos 2017 a 2020. Como uma das bibliotecas do sistema sendo avaliado é aberta ao público externo à universidade, estudantes de graduação de outras instituições também foram convidados a participar do estudo. A quem aceitou o convite foi compartilhada a lista de tarefas pelo WhatsApp, e o link do Google Meet para que a primeira autora pudesse observá-los realizando as tarefas, sendo que a maioria das 
observações foram gravadas, com o consentimento do participante, para posterior consulta se restassem dúvidas.

Para realizar a observação dos participantes, foram seguidos os seguintes passos:

- Contato pelo WhatsApp: Boas-vindas dadas ao participante, explicando a pesquisa e tirando dúvidas. Neste contato inicial, foi feita uma breve conversa com o/a participante consultando: faixa etária; conhecimento da Web (pouco, médio, muito); tempo usual diário de navegação.

- Em seguida, foi apresentada a lista de tarefas (e compartilhada pelo WhatsApp) e o link do Google Meet para que a tela do participante fosse compartilhada para permitir a observação enquanto realizava as tarefas da lista. O Quadro 1 abaixo apresenta a lista de tarefas que foram realizadas pelos participantes:

\section{Quadro 1 - Tarefas que os participantes da pesquisa realizaram}

\section{Tarefas realizadas no sistema de bibliotecas do IES}

1. Entrar no website do Sistema de Bibliotecas (URL fornecido);

2. Localização de Informações:

a. Localize a Biblioteca NOME;

b. Localize o horário de funcionamento desta Biblioteca;

c. Localize o catálogo;

d. Consulte no catálogo a localização do livro: Cidade de Deus por Paulo Lins;

e. Identifique onde você encontraria esse livro fisicamente na Biblioteca (ex: o andar,a estante, o bloco, etc.).

3. Voltar para à página inicial (página Web) do sistema de bibliotecas;

4. Terminada essa fase, por favor entre no link e responda o questionário no Google.

Fonte: Dados da pesquisa (2020)

- Início da gravação, no ambiente do Google Meet, para observação das tarefas sendo executadas pela/o participante. No Quadro 2 a seguir, são apresentadas as ações que foram executadas e observadas durante o compartilhamento de tela, junto com os critérios usados para avaliar cada ação. 


\section{Quadro 2 - Ficha utilizada para observar os participantes na realização das tarefas}

\begin{tabular}{|l|l|l|l|l|l|}
\hline & $\begin{array}{c}\text { Navegação } \\
\text { fácil } \\
\text { S/N }\end{array}$ & $\begin{array}{c}\text { Pede } \\
\text { ajuda } \\
\text { S/N }\end{array}$ & $\begin{array}{c}\text { Utiliza } \\
\text { barra de } \\
\text { rolagem } \\
\text { S/N }\end{array}$ & $\begin{array}{c}\text { Tarefa } \\
\text { completada } \\
\text { S/N }\end{array}$ & $\begin{array}{c}\text { Comentários } \\
\text { gerais }\end{array}$ \\
\hline AÇÕES EXECUTADAS & & & & & \\
\hline Localizar Biblioteca NOME & \multicolumn{2}{|l|}{} & & & \\
\hline $\begin{array}{l}\text { Horário funcionamento } \\
\text { desta biblioteca }\end{array}$ & & & & & \\
\hline Localizar o Catálogo & & & & & \\
\hline $\begin{array}{l}\text { Localizar livro: } \\
\text { Cidade de Deus }\end{array}$ & & & & & \\
\hline $\begin{array}{l}\text { Disponibilidade do livro e sua } \\
\text { localização física na biblioteca }\end{array}$ & & & & & \\
\hline $\begin{array}{l}\text { Voltar página inicial do } \\
\text { sistema de bibliotecas }\end{array}$ & & & & & \\
\hline
\end{tabular}

Fonte: Dados da pesquisa (2020)

- Agradecimento e final de gravação.

Na primeira versão da ficha de observação, tínhamos incluído uma coluna para registrar o número de cliques feito no mouse quando o participante estava navegando no site. Porém, depois de termos realizado as primeiras gravações dos participantes executando as tarefas, percebemos que a visualização e escuta do participante "clicando" no mouse foram inviáveis, e resolvemos focar a atenção exclusivamente na tela do computador (e em alguns casos, do telefone) do participante.

Participaram da pesquisa 31 graduandos, contatados entre 22 de julho a 08 de agosto de 2020. Estes tomaram entre 4 a 15 minutos para a realização das tarefas. Após realizada esta etapa de observação, os participantes foram convidados a responder o questionário elaborado e disponibilizado na plataforma Google Forms. Este foi composto por sete questões fechadas e objetivas, utilizando-se de escala Likert de cinco valores, para medir opiniões, atitudes e percepções dos participantes quanto à facilidade de navegar no sistema. As questões foram baseadas na realização prévia das tarefas; por exemplo, questão número 6 foi: "Indique, numa escala de 1 a 5, o quão fácil você achou para chegar no resultado da pesquisa, sendo que 1 indica 'nada fácil' e 5 'muito fácil." Princípios mais gerais a respeito da usabilidade aparecerem em questões como a 7, que foi: "A respeito da linguagem de navegação do site, indique, numa 
escala de 1 a 5 , quão clara e fácil seja de entender, sendo que 1 indica 'nada fácil' e 5 'muito fácil." Uma variação da escala apareceu na primeira pergunta, que solicitou o grau de concordância com o enunciado: "1. O site apresenta as funções necessárias para que você consiga executar as tarefas (ajuda, consulta, pesquisa), sendo que 1 indica 'discordo totalmente' e 5 indica 'concordo totalmente."

A utilização do Google Forms para elaborar o questionário nos permitiu representar em gráficos as respostas compostas pelas opiniões e sugestões dos participantes, algumas das quais apresentaremos na seção a seguir, junto com nossa análise das mesmas.

\section{RESULTADOS E DISCUSSÃO}

Participaram da pesquisa um total de trinta e um (31) graduandos ingressantes nos anos 2017 (3 participantes), 2018 (19 participantes), 2019 (3 participantes) e 2020 (6 participantes), sendo 25 do total de participantes do curso de Bacharelado em Biblioteconomia e Ciência da informação, e os demais seis de uma variedade de cursos (Farmácia, Administração, Veterinária, Letras e Fisioterapia) de outras universidades ou faculdades: UNESP, UNICEP, FZEAUSP, FATEC. Como a pesquisa iniciou com a observação dos participantes realizando a lista de tarefas, no que segue, descreveremos alguns dos resultados dessa etapa, seguida pela apresentação dos resultados da aplicação do questionário.

\subsection{Dados Coletadas Durante a Observação}

Quanto ao tempo para a realização de todas as tarefas, três participantes as realizaram em menos de quatro minutos (participantes esses que, à época, realizavam estágio na biblioteca objeto da pesquisa) e os demais 28 participantes realizaram as tarefas entre 5 e 15 minutos.

A primeira tarefa foi a de localizar uma biblioteca específica a partir da página principal do Sistema de Bibliotecas sendo pesquisado. Pudemos verificar que todos os participantes localizaram intuitivamente a biblioteca indicada, 
utilizando o mouse para navegar sem a necessidade de utilização da barra de rolagem e sem pedirem ajuda. Cabe notar que na página principal do Sistema de Bibliotecas, consta no menu do lado esquerdo todas as bibliotecas integrantes do mesmo, com o nome da cidade onde cada se localiza. A facilidade de todos os participantes em encontrarem 0 site especificado no roteiro subsequentemente foi refletida nas respostas dadas à pergunta do questionário sobre o conhecimento que possuem da Web, que ficaram distribuídas entre as opções "médio" (26 participantes) a "muito conhecimento" (5 participantes).

A segunda tarefa indicada na lista foi de procurar a informação do horário de funcionamento da biblioteca especificada. Verificou-se que 25 do total dos 31 participantes encontraram de alguma forma o horário de funcionamento, mesmo limitando-se ao uso da barra de rolagem do lado direito da tela. Vários desses já tinham procurado essa informação no menu horizontal (verde) localizado na parte superior da página, clicando com o mouse na opção "serviços e informações", que muda para a cor vermelha ao passar o mouse e não contém a informação procurada. É notável que seis participantes não encontraram onde se localizava o horário de funcionamento. Como respostas ao questionário, alguns participantes observaram que o horário de funcionamento, bem como os telefones e o e-mail, poderiam estar melhor sinalizados, inclusive com layout de outra cor, para que fossem mais facilmente encontrados, uma vez que é necessário rolar a barra até o final da página para encontrar essas informações.

De fato, a informação sobre o horário de funcionamento da Biblioteca se encontra no rodapé da página principal da mesma, junto com seu endereço postal, em tamanho de fonte da letra muito pequeno, como verbalizado por um participante. É relevante aqui citar Nielsen (2007, p. 45) quando observa que: "[...] a maioria dos usuários não rola por uma página e quando o fazem não rolam muito" e acrescenta que: "Se estiver projetando páginas da Web, você deverá levar esse fato em consideração e certificar-se de apresentar informações suficientes acima da dobra para fazer com que eles queiram ver o que está abaixo dela" (NIELSEN, 2007, p. 45). A grande maioria dos participantes não encontrou essa informação logo de início. Sendo uma biblioteca aberta à comunidade externa à universidade, foi notável que os participantes que são 
graduandos de outras instituições, demoraram para localizar o horário de funcionamento, pois não usaram a rolagem da barra.

A segunda tarefa dada aos participantes foi de localizar o catálogo da Biblioteca, bem como o nome do catálogo. Embora 21 dos participantes da pesquisa soubessem que o catálogo se chama Pergamum e conseguiram acessar facilmente, dois participantes comentaram que não se lembravam do nome dele. A porção de 8 participantes não sabia nem o nome do catálogo e tampouco onde acessá-lo, incluídos nessa porção tanto graduandos da mesma instituição da Biblioteca sendo pesquisada, quanto os participantes de outras IESs. Podemos concluir que todos os integrantes dessa porção não tinham familiaridade com a nomenclatura dos produtos e serviços da Biblioteca, e que se a página da Biblioteca tivesse usado o termo mais geral de "Catálogo" ou ainda "Pesquisa no acervo", ao invés do nome comercial do software Pergamum para um serviço tão importante ofertado pela Biblioteca, o acesso seria mais fácil e prático. De fato, o termo "Catálogo" nem aparece no menu principal de serviços ofertados pela Biblioteca.

Cabe lembrar que o catálogo é o coração de toda biblioteca e o elemento no qual os usuários realizam suas buscas para atender às suas necessidades de informação. Em sites de bibliotecas, o acesso ao acervo deve ser de fácil localização, principalmente em se tratando de uma biblioteca universitária que não só a comunidade acadêmica utiliza. Como observa Serra (2014, p. 20):

A biblioteca não é mais uma instituição que atende seu público tradicional, mas pode vir a atender qualquer solicitação, vinda de qualquer local do planeta, em horários díspares. Ao expor seus acervos para pesquisa na Internet, a instituição permite que os usuários identifiquem e acessem os textos completos de forma dinâmica, atendendo a demanda de imediatismo do usuário atual.

Ao longo dessa pesquisa, algumas mudanças ocorreram em vista da pandemia, e todas as instituições públicas e privadas encontram-se fechadas. Nesse contexto, a usabilidade do site de bibliotecas universitárias passa a ser imprescindível em vista do aumento na necessidade de interação dos seus usuários. 
A próxima tarefa solicitada aos participantes foi a de consultar o catálogo para localizar o livro Cidade de Deus, de Paulo Lins, numa das bibliotecas do Sistema de Bibliotecas sendo estudado. Para aqueles participantes que não tinham conseguido localizar o catálogo na tarefa anterior, a pesquisadora realizando a observação informou-lhes como acessá-lo para realizar esta tarefa. Uma vez aberto o catálogo, a barra de busca é bastante fácil e intuitiva. A pesquisa pode ser feita pelo título da obra, autor ou assunto do item. Pode-se ainda filtrar pelo nome da biblioteca do Sistema de Bibliotecas em que se deseja encontrar o exemplar. Verificou-se que 28 dos 31 participantes facilmente conseguiram pesquisar pelo título do livro, também selecionando o nome da biblioteca indicada na lista de tarefas. No entanto, nenhum participante acessou a aba "índices", sendo que se tivessem selecionado "índice título", teria tornado a busca mais precisa. Como resultado, a maioria desses 28 participantes recuperou várias obras catalogadas no acervo com o mesmo título, porém de outro autor, obrigando-os a utilizarem o mouse e a barra de rolagem na lista dos resultados recuperados para identificar a obra solicitada. Também foi observado que embora recuperassem a entrada correta no catálogo na lista dos resultados, como não costumam utilizar a barra de rolagem até o final da página (onde se encontrava os dados da obra), três participantes acharam que não tinham encontrado a obra. Estes requisitaram ajuda para a pesquisadora realizando a observação, que indicou a utilização da barra de rolagem para localizar a entrada da obra no catálogo.

A próxima tarefa foi a de registrar os dados referentes à localização física da obra da tarefa anterior: o andar, o bloco e a estante. Vinte e cinco (25) dos participantes navegaram por várias abas e só no final de várias tentativas e erros e pedidos de ajuda à pesquisadora conduzindo as observações, é que encontraram a aba que se chama "exemplares", que fornece dados sobre a localização física do livro na biblioteca. Os outros seis pediram ajuda imediatamente da pesquisadora, pois compreensivelmente, não relacionaram o rótulo "Exemplares" com informação sobre a localização física da obra. Em suma, a identificação da localização dos exemplares exigiu que os participantes navegassem muito com o mouse e abrissem várias abas para se eventualmente 
fossem retirar o livro, eles soubessem a sua localização física na biblioteca. Entendemos que deveria haver uma mudança na interface (e mais especificamente, na nomenclatura usada na rotulagem da mesma) para que 0 usuário encontrasse mais intuitivamente esta informação sobre a localização.

Após realizada essa pesquisa no catálogo, foi solicitado aos participantes que voltassem para a página inicial do Sistema de Bibliotecas. Vinte e oito (28) dos participantes voltaram facilmente à página inicial, fechando a janela de pesquisa do catálogo. Mas os outros três pediram orientação da pesquisadora para sair da janela aberta para voltar à página inicial do Sistema, algo que possivelmente revela mais uma falta de familiaridade com o uso de navegadores no geral, do que a falta de usabilidade da interface do sistema, já que é mais usual abrir uma nova aba no navegador para usar outro recurso vinculado, deixando aberta a aba original do "ponto de partida" (neste caso específico, a página do Sistema de Bibliotecas) para facilitar a volta a ela depois.

\subsection{Respostas AO Questionário}

Como mencionado, após ter feito as tarefas, a pesquisadora forneceu um URL ao questionário para que os participantes pudessem fornecer suas impressões e percepções relativas à usabilidade do Sistema e aspectos específicos dele. Aqui, pela questão de espaço, apresentaremos apenas uma parte das respostas.

Haviam três questões do questionário que visaram que os participantes avaliassem a facilidade de uso da interface do site do Sistema de Bibliotecas, do ponto de vista da sua percepção geral das telas, textos, botões e figuras; do ponto de vista de quão fácil seja encontrar e visualizar recursos ofertados pelo Sistema pela interface; e do ponto de vista da facilidade da navegação pelas páginas do site. O Gráfico 1 apresenta os resultados dessas três perguntas. 


\section{Gráfico 1 - Observações sobre a facilidade do uso da interface}

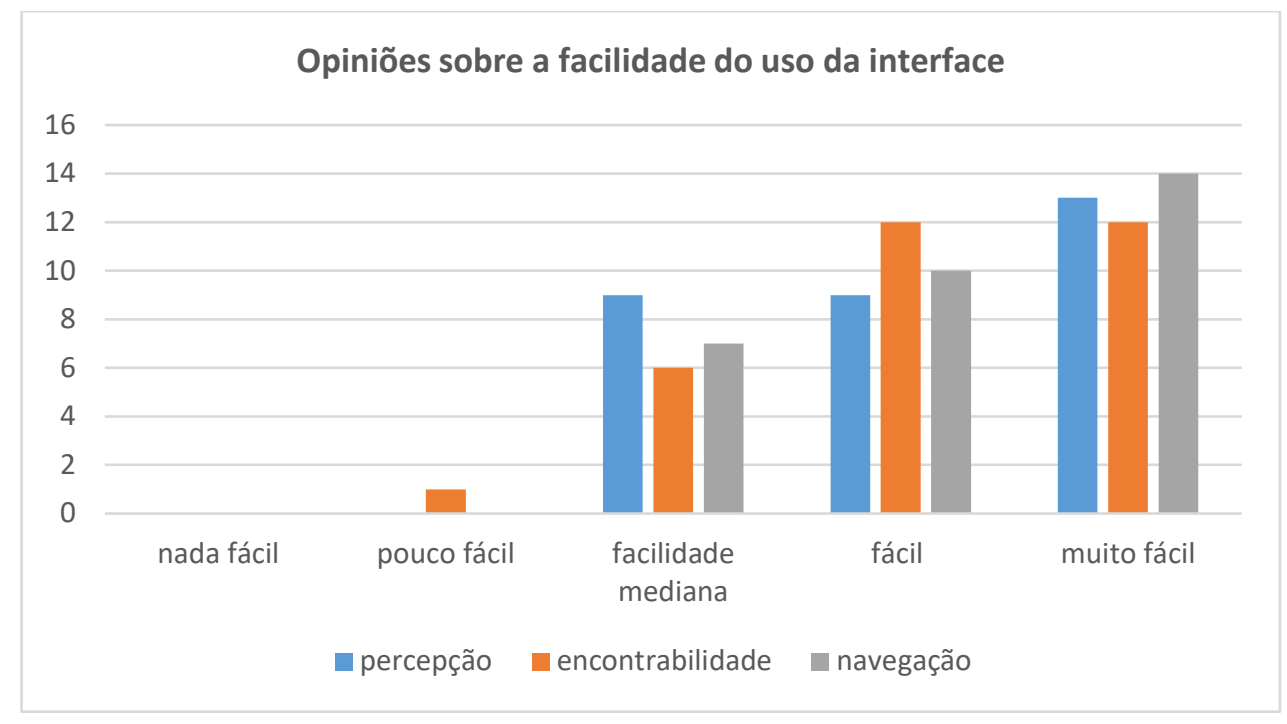

Fonte: Dados da pesquisa (2020)

Observamos que houve apenas um participante da pesquisa que opinou achar que os recursos ofertados pelo Sistema são pouco facilmente encontrados na interface, embora este resultado não pareça refletir o fato que houve mais de um participante da pesquisa de observação que pediu ajuda da pesquisadora para encontrar certos recursos na interface. Mas o fato que a maioria dos participantes concentra nos pontos da escala Likert que sinalizam facilidade e muita facilidade (na percepção geral deles e no que diz respeito à encontrabilidade dos recursos) é um bom resultado na avaliação desta interface. Após cada questão, foi deixado um campo de texto para os participantes acrescentar, opcionalmente e em linguagem natural, seus comentários sobre a questão. No questionário, o enunciado foi: "Caso queira, comente abaixo." Vários participantes aproveitaram dessa oportunidade em cada questão, fato que surpreendeu e agradou às pesquisadoras, que entenderam que a oportunidade de comentar, "ser ouvido" possivelmente aponta para o fato que há pouco espaço - virtual e presencial - para os usuários desse Sistema interagiram com os gestores dos mesmos. Esse fato também levanta outro: que ao realizar pesquisas de avaliação junto aos usuários, podem haver maiores expectativas dos mesmos em relação a possíveis melhorias do sistema depois da pesquisa, que nos fez refletir que talvez deveria ter havido, no Termo de Consentimento Livre e Esclarecido (TCLE), um item que explicitasse aos participantes que os 
resultados da pesquisa não iam necessariamente reverter em intervenções de mudanças na interface. O Quadro 3 traz alguns dos comentários mais críticas das respostas livres dos participantes que entendemos ser muito pertinentes a uma avaliação qualitativa da interface:

\section{Quadro 3 - Respostas livres menos favoráveis a respeito da interface}

"Para uma pessoa que esteja acessando pela primeira vez é complicado achar a funcionalidade de cada botão."

"Acredito que o usuário não associe no primeiro acesso Pergamum com catálogo de livros."

"Eu acho que o uso das mesmas cores no site todo, contribui para a ideia de desorientação do usuário. Talvez cores diferentes para a página que se abre para os campos Unidade, Fontes de Informação, Divulgações, etc. Talvez isso viesse a diminuir a impressão de que se está navegando a esmo."

"O horário de funcionamento, por exemplo, está no rodapé da página, não muito fácil de localizar."

"A utilização de certas palavras como Pergamum e periódicos, acarretou uma certa dificuldade por eu não saber o significado e não ser uma palavra tão conhecida e usada. E ter algumas imagens como botões de acesso a algumas funções causa uma certa confusão pois aparenta ser apenas imagens informativas simbólicas."

"De início não dá pra entender que você pode procurar por título e autor ao mesmo tempo, e o nome Pergamum invés de "acervo" ou algo similar, pode dificultar que a pessoa entenda onde deve pesquisar as obras."

Fonte: dados da pesquisa (2020)

Quando, em outra questão, foi pedido aos participantes que avaliassem o grau de facilidade para encontrar os dados da localização física da obra da página de resultados da pesquisa, 11 acharam "muito fácil", 17 como "fácil" e 3 de "facilidade mediana", resultado esse que também não corresponde às observações feitas, quando seis participantes pediram ajuda da pesquisadora para localizar os dados sobre a localização física da obra na biblioteca.

Outra questão procurou saber a percepção dos participantes no que diz respeito à linguagem de navegação do site, indicando, numa escala Likert de 1 
a 5, quão clara e fácil seja de entender, inclusive por pessoas com pouca experiência no uso de computadores. Os resultados desta questão estão apresentados no Gráfico 2 a seguir:

\section{Gráfico 2 - Percepções quanto à linguagem de navegação do site}

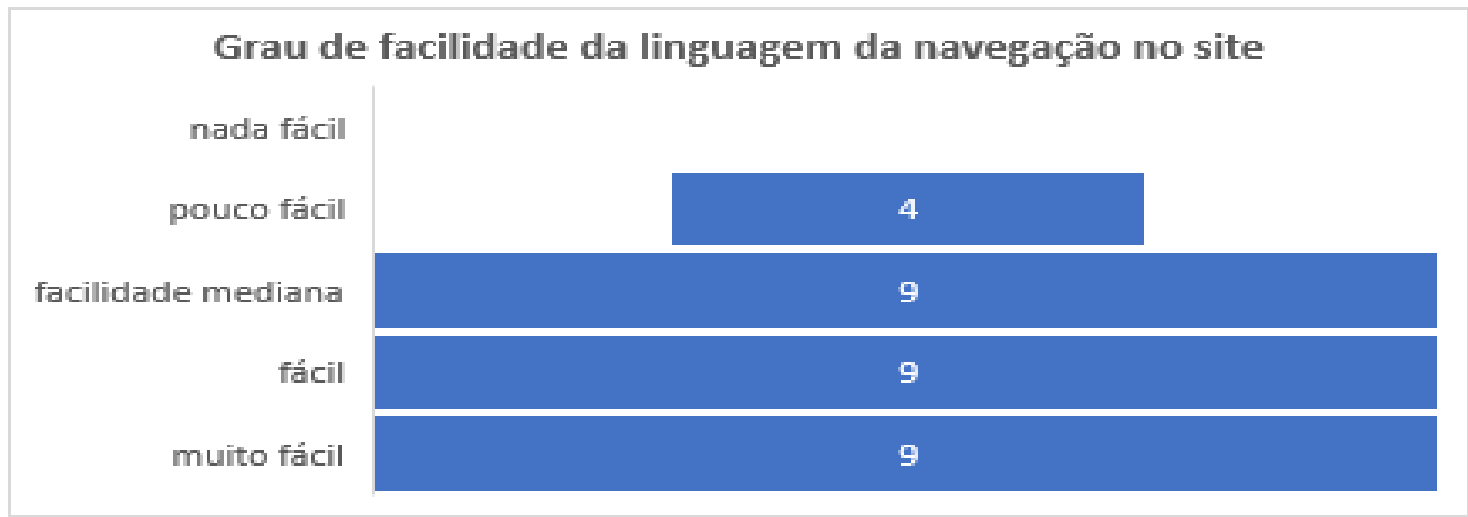

Fonte: Dados da pesquisa (2020)

Nas respostas à questão sobre a linguagem usada para auxiliar o usuário na navegação pelo site, houve quatro participantes que a encontrou pouco fácil. Mesmo aqueles que responderam nas categorias facilidade mediana, fácil e muito fácil, alguns desses fizeram comentários que sinalizaram um grau de consciência do fato que a linguagem pode parecer demasiado técnica para usuários de fora do domínio da biblioteconomia:

"Para uma pessoa com pouca experiência pode ser difícil
associar alguns nomes."
"Acho que pessoas com mais dificuldade demorarão um pouco
para conseguir achar as informações, mas com um pouco de
navegação conseguirão."
"Para quem não tem experiência de navegação e o dialeto da
Biblioteconomia, acredito que não é tão fácil, prático e otimizado
a navegação, poderia haver uma organização melhor do site."

\section{CONSIDERAÇÕES FINAIS}

Considerando a usabilidade da website do sistema de bibliotecas, tal como a usabilidade de alguns dos serviços online de uma das bibliotecas desse 
sistema, concluímos que a observação de usuários pode ajudar aos desenvolvedores de websites e suas interfaces a deixá-los fáceis e práticos na sua utilização, fazendo com que os usuários os percebem como úteis, e assim, que queiram acessá-los. No caso da website do sistema de bibliotecas aqui estudado, a avaliação realizada foi um aprendizado tanto com relação à aquisição de conhecimento de sua interface e algumas funções do site pelos próprios participantes da pesquisa na realização das tarefas, como conhecimento adquirido pelos pesquisadores sobre as dificuldades experimentadas pelos usuários desse sistema, dificuldades essas às vezes não manifestadas nas respostas às questões no questionário. Além das observações realizadas, as respostas às questões abertas do questionário em linguagem natural, mostraram ser um potencial forma valiosa para colher as percepções, opiniões e sugestões dos participantes para subsequentemente constituir um feedback qualitativo de sugestões aos desenvolvedores do referido sistema.

Hoje precisamos de sites que nos levem a informações corretas e seguras. A interface aos serviços do site do sistema de bibliotecas aqui estudado, foi, de modo geral, bem avaliada pelos participantes da pesquisa. Porém, vários deles experimentaram dificuldades em: localizar o horário de funcionamento das bibliotecas do sistema; encontrar no site o catálogo para realizar uma busca simples no acervo; e, após recuperar os dados bibliográficos da busca realizada no catálogo, identificar onde encontrar os dados sobre a localização física da obra no prédio da biblioteca. Entendemos esses resultados reveladores e até graves, pois o serviço básico prestado para qualquer biblioteca é o de, por meio do uso do catálogo, apontar onde, na biblioteca, o usuário encontrará a obra que precisa. Para tal, o usuário também precisará saber 0 horário de funcionamento da biblioteca. Em todos esses quesitos básicos, a interface do sistema de biblioteca foi insatisfatória: isto é, não possui usabilidade fácil para todos seus usuários.

Com base nos resultados do estudo aqui relatado, então, a sugestão é que o catálogo desse sistema de bibliotecas seja melhor nomeado, "rotulado", pois usuários novatos e aqueles de fora da comunidade precisam gastar tempo 
de navegação mais para encontrá-lo e realizar suas buscas, além de que o catálogo remete não só aos livros, mas a várias publicações para consulta de forma digital. $\mathrm{O}$ site também poderia ter mais divulgação junto à comunidade acadêmica da instituição, pois possui muitos recursos que poderiam ser mais bem explorados.

Vivenciando a situação atual, a Web se tornou ferramenta importante na busca de informações. Os sites dependem dos usuários e a usabilidade de sistemas é constantemente testada por eles, involuntariamente, pois se não se identificam, não acham o site interessante, eficiente, de linguagem e aprendizado fáceis, boa visibilização, e fácil aprendizado, ele não será acessado e acabará sendo esquecido.

\section{REFERÊNCIAS}

BARBOSA, S. D. J.; SILVA, B. S. Interação Humano-Computador. Rio de Janeiro: Editora Campus-Elsevier, 2010.

CYBIS, W.; BETIOL, A. H; FAUST, R. Ergonomia e Usabilidade:

Conhecimentos, Métodos e Aplicações. 2. ed. São Paulo: Novatec Editora Ltda., 2010.

DIAS, C. Usabilidade na web: criando portais mais acessíveis. Rio de Janeiro: Alta Books, 2003.

EDLIN, A. S.; RUBINFELD, D. L. The bundling of academic journals. American Economic Review, 2005.

MONTERO, Y. H. Factores del diseño web orientado a la satisfacción y nofrustración de uso. Revista española de documentación científica, Madrid, v. 29. n. 2, p. 339-257, abr./jun. 2006. Disponível em:

https://redc.revistas.csic.es/index.php/redc/article/view/291/353. Acesso em: 21 jan. 2021.

MOURA, M. R. A. InfoMinerva: interface do usuário para sistemas de software do domínio de patrimônio histórico. 2018. 285 f. Tese (Doutorado em Ciência, Tecnologia e Sociedade) - Centro de Educação e Ciências Humanas, Universidade Federal de São Carlos, São Carlos, 2018. Disponível em: https://repositorio.ufscar.br/handle/ufscar/10861 ?locale-attribute=pt_BR. Acesso em: 21 jan. 2021. 
NBR ISO/IEC 9126-1. Engenharia de software. Qualidade de produto, parte 1: modelo de qualidade. Rio de Janeiro: Associação Brasileira de Normas Técnicas - ABNT, 2003.

NBR 9241-11. - Requisitos Ergonômicos para trabalho de escritórios com computadores, parte 11: orientações sobre usabilidade. Rio de Janeiro: Associação Brasileira de Normas Técnicas - ABNT, 2000.

NIELSEN, J.; LORANGER, H. Usabilidade na Web: projetando websites com qualidade. Rio de Janeiro: Editora Campus, 2007.

PADOVANI, S.; SCHLEMMER, A.; SCARIOT, C. A. Usabilidade \& user experience, usabilidade versus user experience, usabilidade em user experience?: Uma discussão teórico-metodológica sobre comunalidades e diferenças. In: CONGRESSO INTERNACIONAL DE ERGONOMIA E USABILIDADE DE INTERFACES HUMANO-COMPUTADOR, 12., 2012, Natal. Anais [...] Natal: 2012, p. 1-10.

ROGERS, Y.; SHARP, H.; PREECE, J. Design de interação: além da interação humano-computador. Porto Alegre: Bookman, 2013.

SERRA, L. G. Livro Digital e Bibliotecas. Rio de Janeiro: FGV, 2014.

VECHIATO, F. L. Repositório digital como ambiente de inclusão digital e social para usuários idosos. 2010. 183 f. Dissertação (Mestrado em Ciência da Informação) - Faculdade de Filosofia e Ciências, Universidade Estadual Paulista, Marília, 2010. Disponível em: https://www.marilia.unesp.br/Home/PosGraduacao/Cienciadalnformacao/Dissertacoes/vechiato_fl_me_mar.pdf. Acesso em: 21 jan. 2021.

VECHIATO, F. L.; VIDOTTI, S. A. B. G. Usabilidade em ambientes informacionais digitais: fundamentos e avaliação. In: CONGRESSO NACIONAL DE BIBLIOTECÁRIOS, ARQUIVISTAS E DOCUMENTALISTAS - BAD, 11., 2012. Lisboa. Anais [...] Lisboa: 2012, p. 1-10. Disponível em: https://publicacoes.bad.pt/revistas/index.php/congressosbad/article/view/457. Acesso em: 21 jan. 2021.

WILDEMUTH, B. M. Aplicações de métodos de pesquisa social a questões em ciência da informação e biblioteconomia. Westport, CT: Libraries Unlimited, 2009.

YESMIN, S.; AHMED, S. M. Z. Preference of Bangladesh University Students for Searching the Library Catalogue: OPAC or discovery tool? The Electronic Library, v. 24, n. 3, set./dez. 2016.

ZAMITE, A. I. S. A Usabilidade do formulário de Catalogação do Sistema de Automação de Biblioteca: Biblivre. Ciência da Informação em Revista, Maceió, v. 3, n. 3, p. 36-46, dez. 2016. Disponível em: https:// 

abr. 21.

\title{
EVALUATION OF THE USABILITY OF A UNIVERSITY LIBRARY SYSTEM WEBSITE
}

\begin{abstract}
Objective: To evaluate the usability of the information search tools of a university library system. Methodology: The research participants (undergraduates) were observed while performing a series of specified tasks. Subsequently, their opinions and perceptions were collected regarding the ease and satisfaction in carrying out and completing the tasks, and the visualisation, availability, and accessibility of resources. Results: it was possible to observe users interacting with the system interface when performing tasks using the scroll bar, mouse, perceiving menu colours, seeking help in several tabs, and evaluate the ease with which users obtained task results and what difficulties were encountered. Conclusion: the research helps system developers to develop easier and more practical interfaces. Regarding library system evaluated here, and particularly regarding the catalogue, this could be better labelled so that it is more easily located, thus helping the user to identify and locate a work in the collection. As an important tool in the search for information on the Web, the system's website must follow the rules of usability for efficiency, with an accessible language, easy learning, and good visibility.
\end{abstract}

Descriptors: Information technology. Usability. Human-computer interaction. Information retrieval

\section{EVALUACIÓN DE LA USABILIDAD DE UN SITIO WEB DE SISTEMAS DE BIBLIOTECAS UNIVERSITARIAS}

\begin{abstract}
RESUMEN
Objetivo: Evaluar la usabilidad de la plataforma de un sistema bibliotecario universitario y el portal de una biblioteca específica de ese sistema. Metodología: Se observó a los participantes de la investigación (estudiantes universitarios) mientras realizaban una serie de tareas. Posteriormente, se les preguntó sobre sus opiniones y percepciones sobre la facilidad y satisfacción en el desempeño de las tareas, y sobre la visualización, disponibilidad y accesibilidad de los recursos. Resultados: Se pudó observar a cada usuario interactuando con la interfaz del sistema utilizando la barra de desplazamiento, mouse, percibiendo los colores del menú, buscando ayuda en las distintas pestañas, evaluando la facilidad con la que cada usuario llegaba al resultado de la tareas y qué dificultades se encuentran. Conclusión: En cuanto al sistema bibliotecario evaluado, y particularmente en cuanto al catálogo, se podría etiquetar mejor para que sea más fácil de localizar, ayudando así al usuario a identificar y localizar una obra en la colección. Como herramienta importante en la búsqueda de información en la Web, el sitio web del sistema debe seguir las reglas de usabilidad para que sean eficientes, con un lenguaje accesible, fácil aprendizaje y buena visibilidad.
\end{abstract}

Descriptores: Tecnología de la información. Usabilidad. La interacción persona- 
ordenador. Recuperación de información.

Recebido em: 27.04 .2021

Aceito em: 09.12.2021 